\title{
AS MÚLTIPLAS FACES E MÁSCARAS DA HETERONORMATIVIDADE: VIOLÊNCIAS CONTRA ADOLESCENTES E JOVENS HOMOSSEXUAIS BRASILEIROS*
}

\author{
THE MULTIPLE FACES AND MASKS OF HETERONORMATIVITY: \\ VIOLENCE AGAINST BRAZILIAN TEENAGERS AND YOUNG HOMOSEXUALS
}

Recibido: 10 de julio de 2017 | Aceptado: 05 de marzo de 2018

DOI: 10.22199/507187475.2018.0001.00003

\author{
IARA FALLEIROS BRAGA 1 ; MANOEL ANTÔNIO DOS SANTOS 2 ; MARILURDES SILVA FARIAS 3 ; \\ MARIA DAS GRAÇAS CARVALHO FERRIANI 3 ; MARTA ANGÉLICA IOSSI SILVA 3
}

1. unIVERSIDADE FedERAL DA PARAíBA, Departamento de Terapia Ocupacional, João Pessoa - Paraíba, Brasil;

2. UNIVERSIDADE DE SÃO PAULO, Faculdade de Filosofia Ciências e Letras de Ribeirão Preto, Departamento de Psicologia e Educação, Ribeirão Preto - São Paulo, Brasil;

3. ESCOLA DE ENFERMAGEM DE RIBEIRÃO PRETO - EERP/USP DEMISP - Departamento de Enfermagem Materno-Infantil e Saúde Pública, Ribeirão Preto - Sc̃o Paulo, Brasil.

\begin{abstract}
RESUMO
INTRODUÇÃO: A violência e preconceito contra a população LGBT tem ganhado destaque na produção acadêmica mundial, evidenciando um número crescente de adolescentes e jovens vitimizados. OBJETIVO: compreender as experiências de violência vivenciadas por adolescentes e jovens que se autodefinem como homossexuais, sob a perspectiva analítica Queer. METODO: Trata-se de um estudo qualitativo, realizado em um município do interior paulista. Participaram 12 adolescentes e jovens, cujo interesse erótico e/ou práticas afetivo-sexuais se voltavam para pessoas do mesmo sexo. A coleta de dados foi realizada por meio de entrevista semiestruturada e os dados foram analisados de acordo com pressupostos do método de interpretação de sentidos, com apoio em conceitos da Teoria Queer. RESULTADOS: a perpetuação de uma cultura heteronormativa e violenta sanciona punições aos dissidentes da norma heterossexual e que adolescentes e jovens que não seguem a suposta linearidade entre sexo, gênero, desejo e práticas sexuais são subalternizados, tornando-se vulneráveis a diver sos tipos de violências e preconceitos, tanto em espaços públicos como privados. CONCLUSÕES: 0 estudo sugere a necessidade de construir uma agenda de pesquisas para melhor compreensão desse fenômeno e delineamento de políticas públicas para sensibilizar e habilitar profissionais na prática do cuidado.
\end{abstract}

PALAVRAS-CHAVE: Violência; Homossexualidade; Adolescência.

\section{ABSTRACT}

INTRODUCTION: Violence and prejudice against the LGBT population have gained prominence in the academic world, showing an increasing number of victimized adolescents and youths. OBJECTIVE: To understand the experiences of violence lived by homosexual adolescents and young people, from the Queer's analytical perspective. METHOD: This is a qualitative study, carried out in county of São Paulo, Brazil. Twelve adolescents and young people, whose erotic interest and/or affective-sexual practices turned to people of the same sex, participated. Data was collected through a semi-structured interview and analyzed according to assumptions of the method of interpretation of meanings, with support in concepts of Queer Theory. RESULTS: Results show that the perpetuation of a heteronormative and violent culture sanctions punishments against dissidents of the heterosexual norm. Adolescents and young people who do not follow the supposed linearity between sex, gender, desire and sexual practices are considered inferior, becoming vulnerable to several types of violence and prejudices, both in public and private spaces. CONCLUSION: The study suggests the need to build a research agenda to better understand this phenomenon and a plan of public policies to sensitize and enable professionals in the practice of assistance.

KEY WORDS: Violence; Homosexuality; Adolescence.

\footnotetext{
Agradecimentos: Ao apoio recebido da Fundação de Amparo à Pesquisa do Estado de São Paulo (FAPESP), processo número 2014/00701-1.

Endereço para correspondência com o Editor: Iara Falleiros Braga. E-mail: iarafalleiros@gmail.com
} 


\section{INTRODUÇÃO}

A violência é um fenômeno complexo e multicausal, que se mantém presente em todas as sociedades e que tem sido destacado tanto no contexto científico, em diversas áreas do conhecimento, quanto no político, frente ao desafio de mobilizar a sociedade a buscar caminhos para seu equacionamento. $\mathrm{Na}$ saúde pública, a violência tem impulsionado 0 desenvolvimento do conhecimento, pois se entende que a exposição às situações agudas ou crônicas de violência afeta a saúde individual e coletiva. Para sua prevenção e tratamento, exige-se a formulação de políticas públicas específicas e a organização de práticas e serviços específicos (Minayo, 2005).

Parte-se da compreensão da violência como produto histórico e cultural, por meio do qual se faz uso da força, das relações de poder e de privilégios para dominar, submeter e provocar danos aos outros, sejam eles indivíduos, grupos ou coletividades, de diferentes faixas etárias (Minayo, 2007). Com relação à natureza dos atos de violência, eles podem ser reconhecidos em quatro tipos: 1) física agressões corporais que produzem lesões, traumas, feridas, dores ou outras incapacidades; 2) psicológica - agressões verbais, gestuais com o intuito de aterrorizar, rejeitar, humilhar, restringir a liberdade ou ainda isolar o sujeito do convívio social; 3 ) sexual - violência que visa estimular ou utilizar a vítima para excitação sexual nas práticas eróticas, pornográficas e sexuais, por meio de aliciamento, violência física e/ou ameaças; e 4) envolvendo negligência abandono ou privação de cuidados ausência, recusa ou abandono dos cuidados necessários do sujeito dependente (Minayo, 2007).

A literatura científica tem priorizado os períodos de transição, como a adolescência e a juventude, como objetos de investigação, devido ao aumento de vulnerabilidade aos danos potenciais da exposição às diferentes expressões de violência. Todavia, as investigações realizadas ainda são excessivamente pautadas nas práticas sexuais e nas questões de sociabilização que envolvem esses períodos críticos do desenvolvimento humano, com poucos estudos voltados para a violência contra adolescentes e jovens dissidentes da norma heterossexual socialmente estabelecida (Citeli, 2005; Soliva \& Silva Junior, 2014).

Adolescentes e jovens que vivenciam sua vida afetiva e sexualidade de forma divergente da "normalidade" heterossexual encontram-se mais expostos a situações de discriminação, preconceito e violências (Fundo das Nações Unidas para a Infância [Unicef], 2011). A estrutura social e comportamentos sexuais que geram preconceitos e atos discriminatórios se fundamentam no dualismo da orientação heterossexual versus homossexual, mas de forma a priorizar a heterossexualidade por meio de um dispositivo que a naturaliza e, ao mesmo tempo, a torna compulsória. Esse dispositivo é a heteronormatividade conjunto de prescrições sociais que vão fundamentar os processos de regulação e controle da manifestação da sexualidade, de modo que todas as pessoas, heterossexuais ou não, pautem suas vidas conforme 0 modelo da heterossexualidade, mantendo a linearidade de seu sexo e gênero (Miskolci, 2009). Já o heterossexismo é a manifestação de preconceito arraigada nas estruturas sociais, nas instituições e nas relações de poder, dificultando o acesso e garantia de direitos da população LGBT. Assim, sujeitos educados a partir desses padrões, com atitudes ou crenças que os reforçam, podem ter atitudes de preconceito contra a diversidade sexual (Costa, Bandeira \& Nardi, 2015).

Os dados sobre violência contra a população LGBT no Brasil no ano de 2013 (Secretaria Especial dos Direitos Humanos, 2013) levantados por meio do Disque Direitos Humanos (DDH - Disque 100) da Secretaria de Direitos Humanos da 
Presidência da República (SDH/PR), apontaram que foram registradas pelo poder público 1.695 denúncias de 3.398 violações relacionadas à população de lésbicas, gays, bissexuais, transexuais e travestis (LGBT), envolvendo 1.906 vítimas e 2.461 suspeitos. A cada dia, durante 0 ano de 2013, do total de casos reportados no país, cinco pessoas foram vítimas de violência homofóbica (Ministério das Mulheres, Igualdade Racial e dos Direitos Humanos, 2016). Foram relatadas nove violações de direitos humanos contra a população LGBT do total de violações no dia. Os adolescentes e jovens continuam sendo as maiores vítimas desta violência no Brasil, ou seja, $61 \%$ das vítimas estão na faixa etária entre 13 e 29 anos (Ministério das Mulheres, Igualdade Racial e dos Direitos Humanos, 2016). A porcentagem de adolescentes e jovens identificados como vítimas se destaca nos levantamentos sistematizados disponíveis. Isso evidencia a importância de se olhar para esse segmento, que se configura como população vulnerável, tanto pela condição da própria faixa etária, quanto pela violência e exclusão a que estão expostos por romperem com o padrão hegemônico fixado social, cultural e historicamente - a heterossexualidade.

Os resultados das pesquisas realizadas pelo Centro Latino Americano em Sexualidade e Direitos Humanos/Instituto de Medicina Social/Universidade do Estado do Rio de Janeiro (CLAM/IMS/UERJ) Centro de Estudos de Segurança e Cidadania/Universidade Cândido Mendes (CESeC/UCAM) em diversas capitais brasileiras com participantes da Parada do Orgulho LGBT durante quatro anos também apontam para dados significativos (Carrara, Ramos, \& Caetano, 2004; Carrara \& Ramos, 2005; Carrara, Ramos, Simões, \& Facchini, 2006; Carrara, Ramos, Lacerca, Medrado, \& Vieira, 2007). Nesta pesquisa, os resultados relacionados à violência e discriminação assim se apresentam: entre $61 \%$ e $65 \%$ dos LGBT entrevistados neste estudo ao menos um episódio de discriminação foi identificado, com base na sexualidade ao longo da vida e entre $56 \%$ e $72 \%$, ao menos um episódio de agressão (Carrara, Ramos, Simões, \& Facchini, 2006). Os tipos de violência e discriminação identificados nestes estudos variaram de acordo com marcadores sociais de diferença; como, sexualidade, gênero, classe social, etnia e geração. As mulheres relataram menos que homens; o percentual de relato decresce conforme aumenta o nível de escolaridade; é menor, também, entre brancos e entre os que têm menos de 22 anos ou mais de 40 (Facchini, França, \& Ventura, 2007).

De acordo com o levantamento realizado pela SDH/PR, por meio das denúncias do Disque 100 no ano de 2012, a violência contra a população LGBT mais referida foi a psicológica, totalizando 83\% (Secretaria Especial dos Direitos Humanos, 2013). Em um estudo transversal, realizado no Estado do Ceará com 316 indivíduos LGBT, a violência psicológica foi identificada em 249 pessoas, que configuravam $79 \%$ da amostra, indicando que essa manifestação de violência é a mais prevalente e, ao mesmo tempo, a mais difícil de ser visibilizada, por estar arraigada na cultura e entranhada nos mecanismos simbólicos de poder. Esse dado sugere que a violência psicológica contribui para naturalizar e perpetuar as práticas de discriminação contra a diversidade sexual (Albuquerque, Garcia, Alves, Queiroz, \& Adami, 2013).

Dois estudos desenvolvidos nos Estados Unidos constataram que a violência sofrida por adolescentes e jovens afetam sua saúde mental e qualidade de vida, com aumento de quadros depressivos, bem como da ideação e tentativa de suicídio (Russell, Ryan, Toomey, Diaz, \& Sanchez, 2011; Ryan, Huebner, Diaz, \& Sanchez, 2009). Um estudo realizado com 7.185 jovens brasileiros analisou o quanto o estigma sexual, associado a baixas condições socioeconômicas, potencializa a exposição à violência sexual e a ideação e tentativa de suicídio (Costa, Pasley, Machado, Alvarado, 
Dutra-Thomé, \& Koller, 2017).

Esse quadro de violência se agrava diante do cenário sociopolítico brasileiro, que apesar de ter implementado políticas públicas importantes no combate à violência contra a população LGBT, através do Programa Brasil sem Homofobia, em 2004, do Plano Nacional de Promoção da Cidadania e Direitos Humanos de Lésbicas, Gays, Bissexuais, Travestis, Transexuais e Transgêneros em 2009, da Política Nacional de Saúde Integral de LGBT, em 2011, o projeto de educação de combate à homofobia (Escola sem Homofobia) foi desenvolvido e custeado pelo próprio Governo Federal, como parte do Programa Brasil sem Homofobia, também em 2011. No entanto este material, que foi apelidado pejorativamente de "kit gay" - acreditando que o mesmo incentivava os alunos à homossexualidade, foi vetado pela Presidente da República na véspera do seu lançamento, após esta ter recebido em audiência um grupo ligado à bancada conservadora do Congresso (Câmara e Senado Federal), parte da sociedade civil e organizações religiosas, que exigiram a suspensão imediata do projeto (Brasil, 2009; Mello, 2012).

Já o Projeto de Lei da Câmara (PLC) $n^{0}$ 122/06 (Brasil, 2006), que foi criado para criminalizar atos de discriminação motivados pela orientação sexual, identidade de gênero ou sexo do sujeito discriminado, continuou com sua tramitação paralisada no Senado. 0 PLC 122 visava incrementar uma lei já existente, a saber, a Lei $\mathrm{n}^{0} 7.716$ (Lei Antirracismo) (Brasil, 1989). Desde sua aprovação em 2006 na Câmara dos Deputados, o PLC 122/06 não obteve a aprovação no Senado Federal (Senger, 2014).

Esses retrocessos recentes no Brasil, devido ao impacto de ideias conservadoras e à entrada da assim chamada "ideologia do gênero", arraigada nos pressupostos heteronormativos e heterossexistas, disseminam 0 ódio à diferença $e$ potencializam a violência e o preconceito à que essa população está sujeita.

Diante do exposto, este estudo teve como objetivo compreender as experiências de violência vivenciadas por adolescentes e jovens homossexuais, sob a perspectiva analítica Queer. Para tanto, torna-se necessário dar voz ao modo como esses sujeitos significam suas experiências de violência, considerando a relevância de incorporar seus testemunhos e reflexões para uma melhor compreensão do fenômeno. Essas contribuições possibilitam (re)pensar propostas de ações preventivas e interventivas para enfrentar a magnitude da violência e do preconceito sofridos, na busca de equacionar as diferentes maneiras pelas quais eles incidem e são percebidos e vividos por gays e lésbicas.

\section{MÉTODO}

Trata-se de uma pesquisa qualitativa, realizada em um município de médio porte localizado no interior do Estado de São Paulo, Brasil. Participaram 12 adolescentes ou jovens que se reconhecem como homossexuais, de ambos os sexos, com idades entre 14 e 24 anos. A seleção dos participantes foi realizada por meio da técnica de bola de neve (snowball), que se inicia com um participante ou um grupo de participantes que indicam novos sujeitos, que indicarão outros e, assim, sucessivamente, possibilitando ao pesquisador a imersão em seu círculo social (Hanneman \& Riddle, 2009). Os critérios de inclusão foram: ser adolescente ou jovem de ambos os sexos, residentes do município de Ribeirão Preto/SP, cujo interesse erótico e/ou práticas se volte para outros do mesmo sexo.

Utilizou-se como instrumento de coleta de dados um roteiro de entrevista semiestruturada, compreendida como aquela que possibilita, a partir de questões norteadoras, que 0 entrevistado expresse seu pensamento, vivências e significados 
construídos a partir da experiência, participando ativamente no processo da pesquisa (Minayo, 2012). Este roteiro abarcou questões acerca da sexualidade, gênero e experiências de violências e preconceitos vivenciadas e/ou presenciadas em seus cotidianos.

Iniciou-se o contato com os participantes no primeiro semestre de 2015, com o objetivo de possibilitar uma aproximação nos pontos de encontro do público LGBT localizados no município. Em um primeiro contato com cada participante foi detalhado o objetivo da pesquisa, as condições de participação e colhida a assinatura do Termo de Consentimento Livre e Esclarecido para os participantes com idade acima de 18 anos, do Termo de Assentimento para os menores de 18 anos e do Termo de Consentimento Livre e Esclarecido para os pais ou responsáveis pelos adolescentes menores de 18 anos.

Após a concordância dos participantes foram agendados os encontros para a realização das entrevistas, em locais de sua preferência. A maioria das entrevistas ocorreu em locais públicos, porém que assegurasse a privacidade e conforto. Outras foram realizadas nas residências dos participantes, sem a presença de outros membros da família. $O$ tempo médio de duração das entrevistas foi de 90 minutos. Todas foram audiogravadas e transcritas na íntegra pela pesquisadora principal. 0 anonimato dos participantes foi garantido por meio da utilização de nomes fictícios escolhidos pelos próprios entrevistados.

Para a análise dos dados, foi utilizado o método de interpretação dos sentidos (Gomes, Souza, Minayo, Malaquias, \& Silva, 2005). Esse método é fundamentado nos princípios hermenêutico-dialéticos, que buscam interpretar o contexto, as razões e as lógicas de falas, ações e inter-relações entre grupos e instituições. Esse método responde às necessidades da presente pesquisa, uma vez que busca, por meio dos princípios da hermenêutica, compreender 0 sujeito histórico imerso em seu contexto e cultura, e por meio da dialética, interpretar, refletir e problematizar os fatos, as linguagens e os símbolos presentes na investigação. Partese do entendimento de que os indivíduos reconstituem o vivido atribuindo-lhe sentido, e emitem enunciados sobre si mesmos que nos dão pistas de como se constituem como sujeitos em meio a contextos de violência (Brah, 2006).

Assim, desde o início e no decorrer do estudo, a análise dos dados textuais percorreu os seguintes passos: leitura e releitura dos textos constituídos pelas transcrições literais das entrevistas para uma apreensão das singularidades de cada entrevistado, e uma leitura transversal de todo o corpus para identificação do que há de comum nas narrativas, assim como 0 destaque das divergências, para que se possa ter uma compreensão dos conteúdos mais relevantes. Em seguida, buscou-se identificar os sentidos atribuídos por parte dos entrevistados, bem como problematizar as principais ideias explícitas e implícitas contidas nos depoimentos, perseguindo os sentidos mais amplos (socioculturais) subjacentes às falas dos sujeitos da pesquisa. Por fim, buscou-se realizar um diálogo entre as ideias problematizadas, as informações provenientes de outros estudos acerca do assunto e o referencial teórico do estudo, a fim de elaborar uma síntese interpretativa, procurando articular o objetivo da investigação, a base teórica adotada e os dados empíricos encontrados (Gomes, Leal, Knauth, \& Silva, 2012).

Em todas as etapas do estudo foram seguidas as recomendações e orientações da Resolução 466/12 sobre os aspectos éticos que regulamentam as pesquisas com seres humanos. 0 projeto foi aprovado pelo Comitê de Ética em Pesquisa da Escola de Enfermagem de Ribeirão Preto da Universidade de São Paulo (EERP/USP), parecer 013/2015. 


\section{RESULTADOS E DISCUSSÃO}

\section{Caracterização dos participantes}

A Tabela 1 permite visualizar algumas características sociodemográficas dos adolescentes e jovens participantes do estudo.

TABELA 1.

Dados sociodemográficos dos participantes da pesquisa.

\begin{tabular}{lcccc}
\hline Participante & $\begin{array}{c}\text { Idade } \\
\text { (anos) }\end{array}$ & Sexo & Escolaridade & Cor da pele / raça \\
\hline Lipe & 18 & Feminino & Ensino médio completo & Branca \\
Duda & 20 & Feminino & Ensino médio completo & Branca \\
Dakota & 19 & Masculino & Ensino médio completo & Preto \\
Afrodite & 21 & Masculino & Ensino médio incompleto & Pardo \\
Normal & 20 & Masculino & Ensino médio incompleto & Branco \\
Sam & 20 & Feminino & Ensino médio completo & Branca \\
Potter & 22 & Masculino & Ensino médio completo & Branco \\
Cálculos & 17 & Masculino & Ensino superior incompleto & Branco \\
Deturpado & 14 & Masculino & Ensino fundamental incompleto & Branco \\
Chanel & 18 & Masculino & Ensino médio completo & Pardo \\
Biologia & 19 & Masculino & Ensino superior incompleto & Branco \\
Paulo Gustavo & 24 & Masculino & Ensino médio completo & Branco \\
\hline Fonte: Dados coletados pela pesquisadora. & & &
\end{tabular}

Fonte: Dados coletados pela pesquisadora.

Participaram deste estudo 12 adolescentes e/ou jovens homossexuais com idade entre 14 e 24 anos, sendo nove do sexo masculino e três do sexo feminino. Os nomes fictícios foram escolhidos pelos próprios participantes. Em sua maioria eram oriundos de regiões periféricas do município, moradores de regiões que apresentavam graves deficiências de infraestrutura em termos de escolas, unidades de saúde e oportunidades de lazer. Dessa forma, esses adolescentes e jovens relataram buscar 0 centro da cidade para ter acesso a escolas, à cultura e aos espaços de sociabilidade, como praças, shoppings, bares e boates.

Dentre os entrevistados, um frequentava regularmente a escola, nove haviam concluído o ensino médio e dois haviam abandonado os estudos; oito exerciam algum tipo de atividade remunerada, sendo que três conciliavam trabalho e estudos. Dois estavam cursando ensino superior.

Com relação à composição familiar, dois participantes provinham de famílias monoparentais (composta pela mãe e pelo adolescente/jovem), uma era composta pelos tios e pelo jovem, uma vez que o pai havia falecido e a mãe 0 abandonou, e 0 restante vinha de famílias compostas por mãe, pai/padrasto e pelo adolescente/jovem. Nenhum dos participantes estava vinculado a alguma associação ou coletivo LGBT do município.

As vivências de violência experienciadas pelos adolescentes e jovens participantes deste estudo revelaram diversos tipos de situações de agressão às quais foram expostos na vida, tais como: violência física, psicológica, sexual e/ou autoinfligida.

Rompendo com a linearidade entre sexo, gênero e desejo: a violência física como forma de controle da normalidade

A violência física foi predominante entre os participantes, que relataram ter sido vítimas de experiências de agressões físicas em diferentes contextos: família, rua e na escola.

Lipe, uma adolescente que se autodefine como lésbica, afirma que se masculiniza há alguns anos e que declara que, por essa 
razão, tem sofrido violência física na escola e na família. Em seu relato descreve que, enquanto 0 irmão a agredia, por ela ter flertado com uma mulher por quem ele estava interessado, ele dizia:

"Se você quer ser homem, você vai apanhar como um homem. E apanhei feio dele, foi bem complicado" (Lipe).

Quando 0 adolescente rompe com a linearidade entre o sexo, gênero, desejo e práticas sexuais esperada pela sociedade, a violência pode ser uma resposta ao incômodo moral provocado pela quebra dos padrões estabelecidos. A transgressão ao desejo e às apresentações de gênero que são tidas como adequadas e naturais é uma das fontes mais contundentes da violência perpetrada contra o transgressor (Borrillo, 2000).

Outra situação identificada de violência física contra uma adolescente lésbica transcorreu no contexto doméstico e foi praticada pela família de sua namorada, por não aceitar o relacionamento afetivo. De acordo com a entrevistada:

[...] já sofri violência, duas vezes e era da família da minha ex-namorada. A mãe dela ficou sabendo do nosso relacionamento e, no começo, fingia que gostava, deixava de boa a gente. Aí, não sei o que aconteceu, ela pegou raiva, o padrasto dela também, aí a mãe dela veio e me bateu a primeira vez. Eu fiquei quieta, não quis tomar nenhuma providência, aí a gente continuou junto, eu não quis separar dela. Aí ela falava que queria ficar comigo, ela também apanhou por ser lésbica e, aí, na segunda vez, eles foram até o apartamento onde eu moro, foram cinco mulheres lá e me bateram, e aí foi quando eu chamei a polícia e fiz o boletim de ocorrência. [...] "eu vou te matar, você que está corrompendo minha filha", a mãe dela dizia. (Duda)
É possível pensar que, no imaginário da família da ex-namorada, perpassa a noção de que a homossexualidade de Duda é imoral, antinatural e inaceitável, capaz de contaminar e "corromper" a pureza de sua filha. Os atos crescentes de violência podem ser vistos como respostas no sentido de manter o controle e dominação sobre a sexualidade da filha, impedindo que ela seja "desvirtuada" pela má influência exercida pela proximidade com a "amiga", de modo a se reestabelecer o padrão de normalidade. 0 choque familiar é provocado pelo rompimento da matriz heterossexual pela adolescente, o que a colocou em uma zona de abjeção, retirando a legitimidade de sua existência.

O dispositivo da sexualidade visa controlar, dominar e manter a lógica da normalidade, delimitando a verdade e totalizando os sujeitos (Foucault, 1976). Nessa concepção, todos os elementos negativos que se articulam para a interdição do sexo, tais como as proibições, violências e censuras, são somente algumas peças, entre outras, que têm uma função local e tática em uma produção discursiva que dá materialidade a uma técnica de poder.

Os participantes do sexo masculino também relataram ter sofrido episódios de violências físicas recorrentes, que ocorreram, principalmente, nos espaços públicos.

Já fui agredido, porque tentaram me assaltar, eu não tinha nada para ser assaltado, e aí ele [o assaltante] falou assim, que eu era um veado e eu merecia morrer, por causa disso ele ia me bater. E me bateu, me agrediu [...] fiquei com hematomas no rosto. (Potter)

A gente estava, assim, numa praça, eu e meus amigos, e tinha um grupo de amigos também mais distante. $E$ aí era noite, o povo estava bebendo, fumando, zoando e brincando e, no 
meio dessa zoação [...] causou um xingamento, um com o outro, e a gente não esperava é que, da parte deles, alguém fosse vir agredir, que no caso agrediu eu, e na hora foi um choque, eu levei uma voadora muito forte, caí no chão e, em seguida, ele deu mais um chute que acertou o meu braço, ele deu uma voadora nas minhas costelas, eu caí e ele me deu um chute no braço, aí na hora eu levantei, meus amigos estavam juntos ali perto, eu comecei a gritar: "Cê é louco, gente, socorro, socorro" (Afrodite)

Eu cheguei a levar soco no olho por causa disso, porque falaram que eu tinha que virar homem, me deram soco no olho, então isso era todos os dias, era um dia sim, um dia não, era outro dia sim, outro dia não, então isso era repetitivo. (Potter)

[...] foi aqui na Praça, estava eu e meu namorado, a gente estava de mãos dadas, conversando, estava eu, ele e mais dois amigos dele, e foi ficando tarde, aí os amigos dele foram embora e nós fomos embora [...], nisso que fomos indo, dois caras começaram a seguir a gente, e começaram a xingar a gente de veado, dizendo que era pra criar vergonha na cara. A gente não dava nem bola e eles pegaram um pedaço de pau e começaram a correr atrás da gente, e aí se esconderam atrás de um carro, perto da base da polícia ainda, e eles acharam a gente, aí um pegou meu ex-namorado e começou a dar soco nele e eu tentei defender ele e aí um deu uma paulada nas minhas costas e eu caí, aí começaram a dar chutes, socos, pontapés, aí eu comecei a gritar socorro, aí passou um moço de moto e eles pegaram e foram embora, e isso perto da base policial [...] Nós fomos fazer o boletim de ocorrência e eles registraram como assalto, e não foi um assalto. (Paulo Gustavo)
Tais manifestações de violências, praticadas tanto por pessoas conhecidas como desconhecidas, expressam o caráter compulsório da heterossexualidade, que se volta impiedosamente contra aqueles que vivem fora do marco estrito da heterossexualidade, bem como contra aqueles que se afastam dos modelos da masculinidade hegemônica contemporânea (Duque, 2009). A heteronormatividade se reafirma constantemente enquanto norma predominante, punindo de diversas maneiras aqueles que dela se afastam. Os adolescentes e jovens entrevistados compartilharam várias situações em que foram relegados à abjeção, mostrando como se tornaram marcados pelo estigma da transgressão, sendo considerados como desumanos e, por isso, passíveis da violência cruel dos crimes de ódio, que almejam o apagamento das diferenças que se visibilizam de maneira incômoda em seus corpos, gestos e práticas afetivas (Butler, 2001).

A inserção do indivíduo na categoria humanidade é produto da diferenciação sexual, então, aqueles que não se enquadram estritamente nas categorias "feminino" e "masculino" serão sumariamente excluídos (Bento, 2011). Por esse motivo,

Matar um travesti, transexual ou um gay feminino não provoca a mesma ira ou a mesma indignação se comparada ao assassinato de uma mulher biológica, pois tal violência estaria mais identificada com um trabalho de assepsia da humanidade do que propriamente com a violência cruenta [...] a violência e a punição são hierarquizadas (Bento, 2011, p. 99).

Todas as violências físicas relatadas pelos adolescentes e jovens aconteceram sem precedentes (sem um motivo real), e foram perpetradas por pessoas anônimas, sendo desencadeadas pelo fato de que eles expressavam, em seus corpos, a dissidência 
sexual e de gênero, por estarem visivelmente rompendo com a lógica da matriz heterossexual e com os preceitos heteronormativos. Dessa forma, esses marcadores sociais da diferença sexualidade e gênero - implicam na instituição de desigualdades, que estão intimamente relacionadas com as redes de poder que permeiam a sociedade. A norma estabelecida historicamente na sociedade ocidental remete ao homem branco, heterossexual, de classe social superior e cristão. Aqueles que ousarem transgredir essas normas estarão, hierarquicamente, inferiorizados e "marcados" pela desigualdade, podendo ser alvo de preconceitos, exclusões e violências que são percebidas como legítimas por quem as pratica (Louro, 2016).

$O$ fato de o agressor ser anônimo e da violência acontecer, principalmente, no horário noturno, justamente por dificultar a identificação dos ofensores, torna mais difícil inibir os atos violentos, o que potencializa 0 medo, reduzindo a possibilidade de transitar em segurança e de se sentir sujeito pleno de direitos e pertencente aos espaços públicos da cidade em que mora.

[...] eu tenho medo de andar na rua sozinho, à noite, principalmente, porque querendo ou não, mesmo eu sendo um gay discreto, as pessoas percebem que é um gay, elas sabem, né? Ou muitos partem mais para a ignorância, mas hoje em dia a gente é perseguido. (Afrodite)

[...] eu fiquei com medo até de sair na rua, eu ficava tão assim, como eu vou dizer, tão afobado, que eu via um moço de bicicleta, ou um moço de moto, ou dois moços andando junto eu já ficava com medo 'Ah, eles vão me atacar'! (Paulo Gustavo)

A disseminação da violência nos espaços públicos, sem ser coibida por ações de vigilância e proteção do aparelho de segurança do Estado, viola a efetivação da cidadania dos adolescentes e jovens gays e lésbicas. Nota-se que lhes é negado e suprimido o direito básico de ir e vir. Por terem medo de transitar por certos locais públicos, eles e elas se veem constrangidos/as a relegar as manifestações afetivas de sua homossexualidade para espaços estritamente privados e protegidos. De fato, a manifestação de violência e preconceito se dão quando a homossexualidade é reivindicada nos espaços públicos, e parece estar relacionada ao temor dos indivíduos que tem preconceito à diversidade sexual, de que se dissolva a fronteira e a hierarquia da ordem heterossexual, desestabilizando seus alicerces (Borrillo, 2009).

Preconceito, opressão e estigmatização: a violência psicológica permeando seus cotidianos

Em relação à violência psicológica, ou seja, aquela que é evidenciada pela interferência negativa de um sujeito sobre outro, por meio de situações de rejeição, depreciação, discriminação e desrespeito, não deixando marcas físicas, mas gerando consequências deletérias para o bem-estar psicológico da vítima. É um tipo de violência que é difícil de ser identificado, e pode estar abarcado em outros tipos de violência (Ministério da Saúde, 2011). As narrativas dos participantes deste estudo apontam esse tipo de violência como presente em seus cotidianos.

Na verdade, a violência verbal, para uma pessoa que aparentemente é homossexual, que dá para ver que é, ela nunca vai acabar. Eu sempre sofro isso, me acompanha desde a infância. A violência verbal, ela sempre existe, em qualquer lugar que eu vou. Para eu ir no mercado hoje e voltar, eu sou caçoado na esquina numa banca com cinco moleques, tudo bem que eu vivo num bairro pobre, e isso é mais fácil ainda de acontecer, então eu falo que, na verdade, 0 homossexual que aparenta ser homossexual, ele vai 
carregar o fardo do preconceito, da discriminação, até a morte. (Potter)

Nessa escola [em que estudou] a violência era muito pior, assim que você sai da sala, eles te dão chutes, eles te caçoam... Então, na hora do intervalo, para você ter uma noção, eu saía da sala de aula e me escondia na biblioteca, eu me escondia na biblioteca porque sabia que era um lugar em que os alunos não iriam me procurar para eu servir de chacota para eles, e ao mesmo tempo me protegia lá, porque tinha um bibliotecário que eu era amigo. (Potter)

Verbalmente, quando eu passo com meu namorado, a gente ouve: "Ah, olha aqueles dois veados, olha que pouca vergonha", entendeu? Essas coisas a gente ouve até hoje. (Paulo Gustavo)

Quando eu era pequeno, eu sofria bastante, de me xingarem: "e aí, veadinho", esse tipo de coisa. (Biologia)

Porque eu já vi muito disso, muitas senhoras, muitas mulheres, vendo grupos de lésbicas, olham com cara feia, xingando. Eu acho que tem isso sim e tem muito, eu mesmo tenho amigas que me contaram que isso aconteceu várias vezes, de mulheres se manifestarem pelo fato delas serem um casal, por elas estarem andando de mão dadas. Já aconteceu, e isso é muito ruim, né? (Afrodite)

[...] as pessoas me chamavam de sapatão, de macho-fêmea, sempre! (Sam)

[...] eu escuto sempre: "Oh, Sapatão", "Vira homem". E é isso aí, violência é normal na rua, "mas que falta de vergonha na cara", sabe? (Lipe)
Nesses casos, a violência foi caracterizada, principalmente, pelo uso de ofensas, chacotas e termos pejorativos alusivos à orientação sexual dos adolescentes e jovens de ambos os sexos, e ocorreram em espaços públicos e no âmbito escolar.

A Fundação Perseu Abramo realizou um levantamento das violências sofridas devido à orientação ou conduta sexual. $42 \%$ dos participantes relataram terem sido tratados com ironia ou gozação, $31 \%$ foram tratados com grosseria ou ofensas e $21 \%$ foram expostos a situações vexatórias ou constrangedoras, em todos os tipos de ambientes sociais, tais como família (53\%), escola (47\%), trabalho (42\%) e lazer $(26 \%)$ (Prado \& Junqueira, 2011).

Com relação ao contexto escolar, a violência e preconceito contra a diversidade sexual são consentidos e ensinados por meio de mecanismos de discriminações, de exclusão e de exposição ao ridículo, ou seja, a violência é sancionada, uma vez que aqueles que se aproximam e acolhem os sujeitos homossexuais são interpretados como sendo homossexuais também, como se a homossexualidade contagiasse aqueles que estão em seu entorno (Louro, 2016).

Assim, adolescentes e jovens se percebem, desde cedo, como alvos preferenciais de uma espécie de "pedagogia da sexualidade", na qual a escola é uma das instituições que mantêm a legitimação da heteronormatividade, por meio da qual as piadas infames, os apelidos pejorativos e as brincadeiras desqualificantes representam mecanismos de silenciamento, de dominação simbólica, de reafirmação da norma e de exclusão dos que dela divergem (Louro, 2016). Em uma pesquisa realizada com alunos do sexo masculino, com idades entre 9 e 14 anos, em uma escola brasileira da periferia de Belo Horizonte, identificou-se que $90 \%$ dos palavrões utilizados pelos alunos se referiam à sexualidade do ofendido, demonstrando que esse tipo de 
violência está fortemente impregnado no cotidiano dos adolescentes (Roselli-Cruz, 2011).

Além de permear o contexto escolar, a violência verbal também é um fato recorrente no cotidiano dos espaços públicos, tanto que a adolescente Lipe ressalta a "normalidade" desse tipo de violência. Esse dado revela a naturalização da condição inferiorizada em que são colocados os segmentos sociais subalternizados, na qual são ocultadas as relações de poder que estão em jogo, imperando os preceitos da heteronormatividade (Prado \& Junqueira, 2011).

A violência psicológica também compõe o cotidiano dos adolescentes e jovens entrevistados na presente investigação, que reiteraram que são submetidos às mais diversas situações de preconceito, opressão, estigmatização e tratamento diferenciado, dentre outras formas de exclusão que se aplicam aos diferentes. Como consequência mais notável, os participantes destacaram 0 sofrimento de viver com medo de ser atacado, em estado permanente de alerta e vigilância. Também emergiram relatos de agravos à saúde mental mais preocupantes, como a falta de controle da impulsividade levando a ideação e tentativa de suicídio. Esse dado está em consonância com outros achados da literatura (Teixeira-Filho \& Rondini, 2012). De fato, segundo a literatura, quando se comparam, estatisticamente, os adolescentes heterossexuais com os não heterossexuais, verifica-se que esses últimos apresentam maior propensão a pensar no autoextermínio e a tentar efetivamente o suicídio.

[...] não era uma ofensa, era meio que uma pressão, uma pressão que fica em você 24 horas por dia, você está na escola e tem as pessoas olhando para você, te pressionando: "Fala se você é homossexual, fala, fala para mim". Você está no ônibus, você vê as pessoas olhando para você pela tela do seu celular. Você está na faculdade, você vê as pessoas olhando o jeito que você anda, o jeito que você fala. É uma coisa assim, tipo estou sendo observado $100 \%$ do tempo, que é uma coisa mais psicológica. (Dakota)

[...] teve uma vez, num barzinho aqui na avenida D. Pedro, a gente nem estava de mão dadas, estava eu, ele e minha irmã, uma outra irmã minha, e 0 garçom chegou e pediu pra gente para soltar nossa mão porque a gente estava num ambiente de família, que a gente não estava no nosso ambiente pra fazer pouca vergonha [...] "Por favor, soltem a mão porque aqui é um lugar de família e tem criança, vamos respeitar". (Paulo Gustavo)

[...] quando eu namorava, eu estava abraçada com a minha ex na escada rolante do shopping, e o guarda foi lá e pediu pra gente não ter muita proximidade física porque o local era familiar. Eu olhei para ele e falei: "Olha, da mesma forma que qualquer um abraça suas namoradas, eu também posso. E outra, se for proibido fazer isso, tem que ser para todo mundo". Eu não deixei de abraçar ela. (Sam)

No presente estudo, um dos participantes também reportou ideação e tentativa de suicídio, atribuindo-a ao sofrimento suscitado pela rejeição social e familiar.

Eu mesmo, na adolescência, pensei em me suicidar. Eu pegava... minha tia tinha remédio e eu tomava remédio da minha tia. Isso com 14 anos, eu comecei a tomar remédio da minha tia, que era antidepressivo, eu ia lá e tomava os remédios [...] Tudo isso porque a minha cabeça era uma panela de pressão, e aí eu chegava em casa e ainda tinha os meus tios me cobrando, porque eles não me aceitavam. (Potter) 
Esse tipo de violência é caracterizado como autoinfligida, ou seja, aquela em que o próprio indivíduo se autoagride ou tem pensamentos, ideações e tentativas de suicídio (Minayo, 2007). No caso do participante deste estudo, a ideação e tentativa de suicídio se deu, segundo seu relato, devido ao impacto em sua saúde mental das violências sofridas. Segundo dados de 2012 da Organização das Nações Unidas (ONU), mais de 800 mil pessoas morrem por suicídio todos os anos no mundo, sendo a segunda principal causa de morte entre jovens com idade entre 15 e 29 anos, sendo que $75 \%$ dos suicídios ocorrem em países de baixa e média renda (World Health Organization [WHO], 2010). A Organização Mundial de Saúde (OMS) reconhece que as taxas de suicídio são mais elevadas em grupos vulneráveis que sofrem discriminação, tais como os refugiados, migrantes, indígenas, LGBT e pessoas privadas de liberdade (WHO, 2014).

Corpos abjetos e objetos: a violência sexual como punição pelo desvio da heterossexualidade

A violência sexual também foi relatada pelo mesmo participante, que sofreu abusos por parte do pai, dos amigos e vizinhos.

[...] fui molestado por meu pai, não abusado em si, não teve penetração nem nada, mas meu pai chegou a me molestar, ele tirava a roupa, ficava mostrando o órgão sexual, passava a mão... (Potter)

Eu tinha amigos que me xingavam, me discriminavam na escola e, ao mesmo tempo, eles pegavam e gostavam de ficar passando a mão, me alisando, todas essas coisas. (Potter)

[...] com 12 anos eu já mantinha relação sexual, não uma relação, assim, que tivesse tanto contato com penetração, essas coisas, mas eu tinha bastante relação, assim, oral. Os meninos, por exemplo, na época que eu tinha 13, 14 anos, eu tinha vizinhos que vinham em casa e até então eles chegavam aqui para perguntar, tudo da mesma idade, vizinhos de 13, 14, 15 anos, que eles procuravam a gente com a desculpa de chamar para jogar videogame e essas coisas, e chegava na hora o menino pegava e começava a fazer outras coisas, entendeu? (Potter)

De acordo com dados do relatório de violência contra a população LGBT no Brasil (Secretaria Especial dos Direitos Humanos, 2013) foram notificadas 74 denúncias de violência sexual contra a população LGBT brasileira. Desses registros, $43,2 \%$ eram de abuso sexual, seguidos por estupro (36,5\%), exploração sexual $(9,5 \%)$ e exploração sexual no turismo $(1,4 \%)$ (Ministério das Mulheres, Igualdade Racial e dos Direitos Humanos, 2016). Esse tipo de violência é favorecido pela construção da imagem social do homem homossexual como indivíduo promíscuo, somado ao estigma da ilegitimidade de sua sexualidade, que não é inteligível na matriz heterossexual. A violência sexual também pode ter um significado de "correção", isto é, ser aplicada como punição pelo desvio da heterossexualidade (Ministério das Mulheres, Igualdade Racial e dos Direitos Humanos, 2016).

A homossexualidade, desde a sua criação como uma categoria médica relacionada à perversão sexual, foi entendida como uma manifestação fundada em uma sexualidade desviante, descontrolada e associal, e como tal, volúvel. A sexualidade de homens gays e mulheres lésbicas é estigmatizada e condenada por romper com a associação entre sexo e reprodução, o que leva à suspeita de que não está sujeita ao controle racional, nem pode ser exercida de um modo socialmente responsável. Faz parte do imaginário social a crença de que os homossexuais são seres lúbricos, devassos e mentalmente perturbados, dotados de uma sexualidade exuberante e insaciável, que os deixaria 
inclinados à promiscuidade ou a práticas ilícitas, como a pedofilia (Miskolci, 2007).

No caso do participante Potter, a violência sexual foi perpetrada pelo pai $e$, posteriormente, reiterada e continuada por amigos, que, ao mesmo tempo em que rejeitavam e humilhavam 0 adolescente, também abusavam sexualmente dele. Esse relato estimula uma reflexão sobre a apropriação que é feita dos corpos desviantes, corpos que são extremamente sexualizados e facilmente se tornam objetos e abjetos, ou seja, ilegítimos e, por isso, acabam sendo reconhecidos como passíveis de atos violentos.

Foram encontradas diversas formas de vitimização - especialmente a física e a psicológica - a que foram expostos os/as adolescentes e jovens gays e lésbicas, prevalecendo as agressões físicas. Comparativamente, foram encontrados poucos relatos de agressão sexual, bem como de violência autoinfligida, com ideações suicidas que refletem 0 impacto das múltiplas violências sofridas anteriormente. Os contextos em que essas violências se materializaram foram espaços públicos ou privados, como o lar, a escola e as ruas dos bairros periféricos onde residem.

Homens e mulheres homossexuais relataram que sofreram vários tipos de violência, no entanto, aqueles e aquelas que não performatizaram 0 gênero correspondente ao seu sexo biológico, ou seja, os meninos mais "afeminados" e as meninas mais "masculinizadas", relataram experiências de duplo sofrimento, por não se enquadrarem na linearidade do gênero, a partir do sexo que lhes foi atribuído ao nascimento, e por não manifestarem 0 desejo e as práticas sexuais direcionadas para o sexo oposto. Na perspectiva analítica da teoria Queer, essas manifestações de violência ocorrem como forma de manutenção da heteronormatividade, que sanciona punições e promove exclusões a partir da identificação daqueles que transgridem essa lógica fundamental, reforçando o caráter aberrante da abjeção.

\section{CONCLUSÃO}

Este estudo investigou e analisou, sob a ótica de uma abordagem compreensiva, as experiências de violência vivenciadas por adolescentes e jovens gays e lésbicas. Observou-se que os participantes revelaram exposição a diversas situações de menosprezo, preconceito e discriminação devido à sua orientação sexual e performance de gênero, ao longo de suas trajetórias de vida. Violência física, psicológica, sexual e autoinfligida foram as mais referidas. Ambos os sexos relataram 0 sofrimento decorrente de agressões físicas sofridas em diversos contextos, como a família, a rua e a escola. Os homens vivenciaram violências, especialmente, nos espaços públicos. Já a violência psicológica foi caracterizada, principalmente, pelo uso de ofensas, chacotas e termos pejorativos alusivos à orientação sexual dos participantes, tendo ocorrido em espaços públicos e escolares (bullying).

Foram relatadas situações dolorosas de preconceito, opressão, tratamento diferenciado, dentre outras formas de exclusão. Como consequência dessas vivências perturbadoras, os adolescentes e jovens destacaram os sentimentos de medo e vulnerabilidade ao sofrimento, bem como a suscetibilidade a agravos mais graves, tais como ideações e tentativas de suicídio. Um dos participantes narrou sua experiência de ideação suicida, que culminou com uma tentativa mal-sucedida, desencadeada pelo intenso sofrimento gerado pelas violências acumuladas. A violência sexual também foi descrita pelo mesmo jovem, nesse caso, com a particularidade de que começou com uma relação incestuosa, especificamente por parte do pai. Essa relação abusiva foi depois repetida pelo grupo de pares, que ao mesmo tempo em que o rejeitavam e humilhavam, também o usavam para praticar atos libidinosos. 
Dessa maneira, os resultados deste estudo revelam a tendência à perpetuação de uma cultura heteronormativa e violenta, que sanciona punições àqueles que se diferenciam da norma heterossexual. São adolescentes e jovens que não seguem a linearidade entre sexo, gênero, desejo e práticas sexuais. Quanto mais a quebram, mais serão subalternizados; seus corpos são submetidos a diversos tipos de violência, tanto em espaços públicos como privados.

Evidencia-se que os dados apresentados são contextuais e provisórios e não podem ser generalizados a outros contextos ou grupos sociais. Pesquisas adicionais podem apoiar os conceitos aqui discutidos e expandir as reflexões sobre as experiências de adolescentes e jovens gays e lésbicas que vivenciam a violência, através de diferentes abordagens teórico metodológicas, expandindo a análise para além das questões da sexualidade, mas correlacionando outros marcadores sociais das diferenças, tais como gênero, raça e classe social.

Este estudo busca contribuir com a compreensão das facetas da violência vivenciada por adolescentes e jovens homossexuais e com a produção de conhecimento na área da psicologia, visto serem escassas as pesquisas desenvolvidas acerca desta temática com 0 grupo populacional evidenciado. Destaca-se a necessidade de se construir uma agenda de pesquisas para a melhor compreensão deste fenômeno e para o delineamento de políticas públicas capazes de sensibilizar profissionais e práticas de cuidado e atenção à família e ao adolescente e/ou jovem vítima de violência.

\section{REFERÊNCIAS}

Albuquerque, G. A., Garcia, C. L., Alves, M. J. H., Queiroz, C. M. H. T., \& Adami, F. (2013). Homossexualidade e 0 direito à saúde: Um desafio para as políticas públicas de saúde no Brasil. Saúde em
Debate, 37(98),

516-524.

doi:10.1590/S0103-

11042013000300015

Bento, B. (2011). Política da diferença: Feminismos e transexualidades. In $\mathrm{L}$. Colling (Org.), Stonewall 40 to que no Brasil? (pp. 79-111). Salvador, Bahia: EDUFBA.

Borrillo, D. (2000). L'homophobie. Paris, France: Presses Universitaires de France.

Borrillo, D. (2009). Homofobia. In T. Lionço \& D. Diniz (Orgs.), Homofobia e Educação: Um desafio ao silêncio (pp. 15-46). Brasília, DF: Letras Livres/EdUnB.

Brah, A. (2006). Diferença, diversidade, diferenciação. Cadernos Pagu, (26), 329-376. doi:10.1590/S010483332006000100014

Brasil. (2009). Presidência da República. Secretaria Especial dos Direitos Humanos. Plano Nacional de Promoção da cidadania e dos direitos humanos de LGBT: lésbicas, gays, bissexuais, travestis e transexuais. Brasília: SEDH. Recuperado de http://www.arcoiris.org.br/wpcontent/uploads/2010/07/planolgbt.pdf

Brasil. (2006). Senado Federal. Projeto de Lei da Câmara nº 122 de 2006. Brasília: Senado Federal. Recuperado de http://www.senado.gov.br/noticias/opini aopublica/pdf/PLC122.pdf

Brasil. (1989). Presidência da República. Casa Civil. Subchefia para Assuntos Jurídicos. Lei $n^{0} 7.716$ de 5 de janeiro de 1989. Define os crimes resultantes de preconceito de raça ou de cor. Brasilia: Presidência da República. Recuperado de http://www.planalto.gov.br/ccivil_03/leis /L7716.htm

Butler, J. (2001). Corpos que pesam: Sobre os limites discursivos do sexo. In G. L. Louro (Org.). O corpo educado (pp. 151172). Belo Horizonte, MG: Autêntica.

Carrara, S., Ramos, S., \& Caetano, M. (Coord.). (2004). Política, direitos, violência e homossexualidade: 
Pesquisa 8 a Parada do Orgulho GLBT: Rio 2003. Rio de Janeiro, Pallas.

Carrara, S., \& Ramos, S. (2005). Política, direitos, violência e homossexualidade: Pesquisa $9^{\text {a }}$ Parada do Orgulho GLBT: Rio 2004. Rio de Janeiro: CEPESC.

Carrara, S., Ramos, S., Simões, J. A., \& Facchini, R. (2006). Política, direitos, violência e homossexualidade. Pesquisa 9a Parada do Orgulho GLBT São Paulo 2005 (1a ed.). Rio de Janeiro: CEPESC.

Carrara, S., Ramos, S., Lacerda, P., Medrado, B., \& Vieira, N. (2007). Política, direitos, violência e homossexualidade. Pesquisa $5^{\text {a }}$ Parada da Diversidade - Pernambuco 2006. Rio de Janeiro: CEPESC.

Citeli, M. T. (2005). A pesquisa sobre sexualidade e direitos sexuais no Brasil (1990-2002): Revisão crítica. Rio de Janeiro, RJ: CEPESC.

Costa, A. B., Pasley, A., de Lara Machado, W., Alvarado, E., Dutra-Thomé, L., \& Koller, S. H. (2017). The experience of sexual stigma and the increased risk of attempted suicide in young Brazilian people from low socioeconomic group. Frontiers in Psychology, 8, 1-12.

Costa, A.B., Bandeira, D.R., \& Nardi, H.C. (2015). Avaliação do preconceito contra diversidade sexual e de gênero: construção de um instrumento. Estudos de Psicologia (Campinas), 32(2), 163172.

Duque, T. (2009). Sexualidade, gênero e abjeção: Uma reflexão sobre direitos humanos e LGBT no Brasil contemporâneo. Anais do Seminário Nacional de Sociologia e Política, 1, 219.

Facchini, R., França, I. L., \& Venturi, G. (2007). Sexualidade, cidadania e homofobia: pesquisa da $10^{a}$ Parada do Orgulho GLBT de São Paulo. São Paulo: APOGLBT.

Foucault, M. (1976). Histoire de la sexualité. Tome 1: La volonté de savoir. Paris, France: Gallimard.
Fundo das Nações Unidas para a Infância. (2011). Situação mundial da infância 2011: Adolescência: Uma fase de oportunidades. Recuperado de http://www.unicef.org/brazil/pt/br_sowcr 11 web.pdf

Gomes, R., Leal, A. F., Knauth, D., \& Silva, G. S. N. (2012). Sentidos atribuídos à política voltada para a Saúde do Homem. Ciência \& Saúde Coletiva, 17(10), 25892596. doi: $\quad 10.1590 / S 1413-$ 81232012001000008

Gomes, R., Souza, E. R., Minayo, M. C. S., Malaquias, J. V., \& Silva, C. F. R. (2005). Organização, processamento, análise e interpretação de dados: 0 desafio da triangulação. In M. C. S. Minayo, S. G. Assis, \& E. R. Souza (Orgs.), Avaliação por triangulação de métodos: Abordagem de programas sociais (pp. 185-221). Rio de Janeiro, RJ: Editora Fiocruz.

Hanneman, R., \& Riddle, M. (2009). Introduction to social network methods. Riverside, CA: University of California.

Louro, G. L. (Org.). (2016). O corpo educado: Pedagogias da sexualidade. Belo Horizonte, MG: Autêntica.

Mello, E. P. G. (2012). A homofobia que nos mata todo dia. São Paulo: Rede Social de Justiça e Direitos Humanos. Recuperado de https://homofobiamata.files.wordpress.c om/2012/04/direitoshumanos_2012.pdf

Minayo, M. C. S. (2005). Violência um problema para a saúde dos brasileiros. In E. R. Souza \& M. C. S. Minayo (Orgs.), Impacto da violência na saúde dos brasileiros (pp. 117-140). Brasília, DF: Editora do Ministério da Saúde.

Minayo, M. C. S. (2007). Conceitos, teorias e tipologias de violência: A violência faz mal à saúde individual e coletiva. In $\mathrm{E}$. R. Sousa (Org.), Curso impactos da violência na saúde (pp. 24-35). Rio de Janeiro, RJ: EAD/ENSP.

Minayo, M. C. S. (2012). O desafio do conhecimento: A pesquisa qualitativa 
em saúde (12a ed.) São Paulo, SP: Hucitec.

Ministério da Saúde. (2011). Violência contra a criança e 0 adolescente: Proposta preliminar de prevenção e assistência à violência doméstica. Brasília, DF: Ministério da Saúde. Recuperado de http://bvsms.saude.gov.br/bvs/publicac oes/0220violencia.pdf

Ministério das Mulheres, Igualdade Racial e dos Direitos Humanos. Secretaria Especial dos Direitos Humanos. (2016). Relatório sobre violência homofóbica no Brasil: Ano de 2013. Brasília, DF: Sedh. Recuperado de http://www.sdh.gov.br/assuntos/lgbt/da dos-estatisticos/Relatorio2013.pdf

Miskolci, R. (2007). Comentário. Cadernos Pagu, (28), 55-63. doi: 10.1590/S010483332007000100004

Miskolci, R. (2009). A teoria queer e a sociologia: $O$ desafio de uma analítica da normalização. Sociologias, 11(21), 150-182. doi: 10.1590/S151745222009000100008

Prado, M. A. M., \& Junqueira, R. D. (2011). Homofobia, hierarquização e humilhação social. In G. Venturi \& V. Bokany (Orgs.), Diversidade sexual e homofobia no Brasil (pp. 51-72). São Paulo, SP: Fundação Perseu Abramo.

Roselli-Cruz, A. (2011). Homossexualidade, homofobia e a agressividade do palavrão: Seu uso na educação sexual escolar. Educar em Revista, (39), 7385. doi: 10.1590/S010440602011000100006

Russell, S. T., Ryan, C., Toomey, R. B., Diaz, R. M., \& Sanchez, J. (2011). Lesbian, gay, bisexual, and transgender adolescent school victimization: Implications for young adult health and adjustment. Journal of School Health, 81(5), 223-30. doi: 10.1111/j.17461561.2011.00583.x

Ryan, C., Huebner, D., Diaz, R. M., \& Sanchez, J. (2009). Family rejection as a predictor of negative health outcomes in white and Latino lesbian, gay, and bisexual young adults. Pediatrics,
123(1), $346-$

352. doi: $10.1542 /$ peds.2007-3524

Secretaria Especial dos Direitos Humanos. (2013). Relatório sobre violência homofóbica no Brasil: Ano de 2012. Brasília, DF: Sedh. Recuperado de http://www.rcdh.es.gov.br/sites/default/f iles/RELATORIO\%20VIOLENCIA\%20H OMOFOBICA\%20ANO\%202012.pdf

Senger, D. (2014). Homofobia no Brasil: projetos de lei e políticas públicas em defesa dos direitos da população LGBT e 0 discurso religioso da bancada evangélica. Congresso Internacional da Faculdades EST, 2.. São Leopoldo. Anais... São Leopoldo: EST.

Soliva, T., \& Silva Junior, J. B. (2014). Entre revelar e esconder: Pais e filhos em face da descoberta da homossexualidade. Sexualid, Salud y Sociedad, (17), 124148 doi: 10.1590/19846487.sess.2014.17.08.a

Teixeira-Filho, F. S., \& Rondini, C. A. (2012). Ideações e tentativas de suicídio em adolescentes com práticas sexuais hetero e homoeróticas. Saúde \& Sociedade, 21(3), 651-667. doi: 10.1590/S0104-12902012000300011

World Health Organization. (2010). IMAI oneday orientation on adolescents living with HIV. Geneva, Switzerland: WHO.

World Health Organization. (2014). Preventing suicide: A global imperative. Geneva, Switzerland: WHO. 